\title{
Partial IVC Clamping Improves Intraoperative Hemodynamic Parameters in the Rodent Portacaval Anastomosis Model
}

\author{
Merhdad Asgeri $^{1}$, Nash Waghray ${ }^{1}$, Kevin Mullen ${ }^{1}$, N. Nade ${ }^{3}$, Henri Brunengraber ${ }^{4}$, Juan Sanabria ${ }^{2,4}$ \\ ${ }^{1}$ Departments of Medicine MetroHealth Medical Center and University Hospitals-Case Medical Center, \\ Case Western Reserve University School of Medicine, Cleveland, $\mathrm{OH}$ \\ ${ }^{2}$ Departments of Surgery, University Hospitals-Case Medical Center and \\ Case Western Reserve School of Medicine, Cleveland, $\mathrm{OH}$ \\ ${ }^{3}$ Departments of Anesthesiology and Surgery, VA Western New York Healthcare System, \\ State University of New York at Buffalo, Buffalo, NY \\ ${ }^{4}$ Department of Nutrition, Case Western Reserve University School of Medicine, Cleveland, $\mathrm{OH}$ \\ E-mail: juan.sanabria@uhhospitals.org, juan.sanabria@case.edu \\ Received January 23, 2011; revised February 28, 2011; accepted March 25, 2011
}

\begin{abstract}
The mechanisms involved in the development of hepatic encephalopathy still remain uncertain. The rodent portacaval shunt is a model that reproduces many of the pathological features observed in humans (1), but is a technically demanding exercise. While the traditional technique involves complete occlusion of the IVC, a c-clamp was fashioned to partially clamp the IVC thereby sustaining venous return and cardiac output. The aim of this study is to determine if the c-clamp technique provides greater hemodynamic stability and enhances the success rate of the portacaval shunt procedure. To answer this question, two experimental groups, c-clamp $(\mathrm{N}=7)$ and cross-clamp $(\mathrm{N}=7)$, and a sham group $(\mathrm{N}=3)$ were included. Intraoperative hemodynamic parameters were recorded at specific times during the procedure. The c-clamp group showed greater hemodynamic stability when compared to the cross-clamp group. It was manifested by 1) significantly higher mean arterial blood pressure [63 (range, 8) vs 47 (range, 10) $\mathrm{mmHg}, \mathrm{p}<0.05$ ], 2) faster capillary refill [4 (range, 2) vs 6 (range, 2) seconds, $\mathrm{p}<0.05$ ], 3) higher urinary output [0.18 (range, 0.02) vs 0.14 (range, 0.02 ) $\mathrm{ml}, \mathrm{p}<0.05$ ], and 4) lower bowel wet-to-dry ratio [4.168 (range, 0.258) vs 4.731 (range, 0.271 ), $\mathrm{p}<$ 0.05]. We conclude partial IVC clamping improves hemodynamic stability during the construction of the rat portacaval shunt model.
\end{abstract}

Keywords: Portacaval Anastomosis, Portosystemic Shunt, Microvascular Surgery, Ivc Clamping, Surgical Technique, Encephalopathy-Like Rodent Model

\section{Introduction}

Hepatic encephalopathy (HE) is a complex neuropsychiatric syndrome characterized by global depression of CNS function, progression to impaired consciousness, and coma. The varying severity typically seen in patients is associated with evidence of liver failure and portosystemic shunt formation. Surgical construction of a portacaval shunt in rats reproduces many of the pathological features of portosystemic hepatic encephalopathy in humans [1]. Developed by Lee and Fisher in 1961, the rodent portacaval shunt model has been well validated but remains a technically demanding procedure [2-4]. Hemodynamic instability associated with complete occlusion of both the portal vein and the inferior vena cava remains the underlying factor in mortality rates related to shunt construction $[5,6]$. The instability is manifested in the rat as hypotension, bowel edema, reduction of urine output, and hypovolemic cardiac arrest [5,7-10].

Since the interpretation of experimental work in the rodent portacaval shunt model could be significantly influenced by the performance of the operation and its complications, several technical modifications have been suggested to improve animal survival and shunt patency. 
Changes have focused on reducing the procedural time of portal vein ligation, IVC occlusion, and completion of portacaval anastomosis $[8,11,12]$. We hypothesized that complete occlusion of the IVC substantially reduced venous return and was a major factor in the technical difficulties associated with the traditional cross-clamp method. The concept of partial IVC occlusion is not new; Welch et al. first reported its use for portacaval shunt construction in dogs [13]. Later, Jacob et al. applied this technique to the rodent model [14]. Partially clamping the IVC provides the operator with greater time to construct the anastomosis while limiting the severity of hemodynamic compromise. This is especially important for the surgeon during the learning phase of the procedure. Therefore, we fashioned a micro-serrifine clamp to create a c-clamp that would only partially occlude the IVC. Partial clamping would be verified by direct visualization of the IVC and indirectly by measuring the mean arterial pressure. By sustaining venous return, intraoperative hemodynamic stability would improve and preserve renal function. The current study was designed to evaluate the c-clamp vs the traditional cross-clamp technique in the construction of the portacaval shunt in rats. Refining this animal model of encephalopathy may enhance the interpretation of future research and it translation to the human.

\section{Materials and Methods}

\subsection{Animals}

Male Sprague-Dawley rats weighing 275-325 grams were used for purpose of the present study. After arrival, animals were in quarantine for five days. Healthy rodents were kept in fixed daynight cycles (12h) at standard room temperature and humidity, fed with rat chow and provided with water ad libitum until scheduled for surgery. After completion of the shunt, rats were sacrificed using a high flow of $\mathrm{CO}_{2}$ into the anesthetic chamber. All surgical procedures were approved and performed according to the regulations of the IAIRB at Case Western Reserve University.

\subsection{Hemodynamic Parameters}

In order to evaluate two different techniques in the construction of the portacaval shunt, several intra-operative variables were recorded 1) at the time of skin incision, 2) two minutes after IVC clamp placement, and 3) two minutes after shunt clamp release. They included: mean arterial pressure (MAP), heart and respiratory rates, rectal temperature, capillary refill, bowel color, urine output and intestinal wet-to-dry ratio. The ventral tail artery was cannulated with MRE-33 tubing (0.014 in ID, 0.033 in OD, BrainTree Scientific) and connected via transducer to Digimed BP analyzer machine (Micromed Inc. Model: BPA-400a) to record the heart rate and the blood pressure in $\mathrm{mmHg}$. After lubrication, a rectal thermometer was placed and the temperature was maintained between $37-38^{\circ} \mathrm{C}$ via a heating lamp $[15,16]$. Once the abdominal cavity was entered, the bladder was emptied of urine by manual compression. A non-traumatic clamp was then placed occluding the urethra. Upon shunt clamp release, urine output was measured by suctioning the urine from the bladder with a $1 \mathrm{~mL}$ syringe connected to a $25 \mathrm{G}$ needle. Baseline bowel color and capillary perfusion were evaluated by an observer who had no knowledge as to the type of procedure being performed. Bowel color was identified as pink, pink/purple, or purple. Capillary perfusion was noted by blanching a segment of proximal small bowel, releasing, and recording the refill time in seconds. In order to obtain information regarding intestinal edema, a $6 \mathrm{~cm}$ length of proximal small bowel (beginning two centimeters from the pylorus) was removed immediately after euthanasia. The section of bowel was examined, gently milked dry, and weighed (SargentWelch scale, TL 400-DR). Subsequently, the proximal small bowel segment was placed in a $60^{\circ} \mathrm{C}$ dessicator oven (Quincy Lab Inc., Model: 10-210) and allowed to dry until dry weights were equal. The intestinal wet to dry ratio was determined to provide a measure of intestinal edema [16].

\section{Porto-Systemic Shunt Procedure}

Animals were weighed (Model: Scout Pro SP2001) and placed in a chamber for induction of anesthesia by a gas mixture of Isoflurane: $\mathrm{O}_{2}(2: 98 \%$ at $3 \mathrm{~L} / \mathrm{min})$. Unconscious rodents were positioned in supine position, affixed to a metal board and maintained with a similar gas mixture through a nose cone $(2 \mathrm{~L} / \mathrm{min})$. Time from induction of anesthesia to laparotomy incision, and shunt clamp release (completion of portacaval anastomosis) were recorded (Table 1).

\subsection{Shunt Dissection}

The abdominal wall was shaved and the surgical site was cleaned with alcohol and allowed to dry. A midline incision was made from the bladder to the xyphoid process. Warm moist gauzes in saline solution (NS $0.9 \%$ ) were used to cover and position the abdominal contents to provide a wider surgical field. The area of abdominal contents were irrigated with saline solution (NS 0.9\%) every 10 minutes. An operative scope was positioned (Olympus, 10X). The portal vein was dissected along its 
Table 1. Parameters recorded during construction of portacaval shunt.

\begin{tabular}{|c|c|c|c|c|}
\hline \multicolumn{5}{|c|}{ Rodent Portacaval Shunt Data [Median (Range)] } \\
\hline Variables & Sham $(\mathrm{N}=3)$ & C-Clamp ( $\mathrm{N}=7)$ & Cross Clamp $(\mathrm{N}=7)$ & P-value§ \\
\hline Weight (grams) & $294.4(7.4)$ & $302.7(22)$ & $296.3(20.1)$ & 0.38 \\
\hline Anesthesia Time (minutes) & $77(2)$ & $77(9)$ & $78(6)$ & 0.29 \\
\hline Laparotomy to SCR(minutes)* & $52(1)$ & $55(5)$ & $56(6)$ & 0.22 \\
\hline \multicolumn{5}{|l|}{ Mean Arterial Pressure } \\
\hline Baseline & $114(4)$ & $114(10)$ & $115(8)$ & 0.45 \\
\hline IVC clamp & & $63(8)$ & $47(10)$ & $<0.05$ \\
\hline SCR & $110(4)^{* *}$ & $86(12)$ & $71(9)$ & $<0.05$ \\
\hline \multicolumn{5}{|l|}{ Heart Rate } \\
\hline Baseline & $358(3)$ & $356(16)$ & $358(13)$ & 0.32 \\
\hline \multicolumn{5}{|l|}{ Respiratory Rate } \\
\hline Baseline & $72(4)$ & $72(8)$ & $72(6)$ & 0.37 \\
\hline IVC clamp & & $63(8)$ & $63(9)$ & 0.23 \\
\hline SCR & $71(4)^{* *}$ & $66(11)$ & $67(7)$ & 0.34 \\
\hline \multicolumn{5}{|l|}{ Rectal Temp $\left({ }^{\circ} \mathrm{C}\right)$} \\
\hline Baseline & $37.9(0.6)$ & $38.1(1.6)$ & $37.2(1.6)$ & 0.29 \\
\hline IVC clamp & & $37.3(1.1)$ & $37.4(0.8)$ & 0.26 \\
\hline SCR & $37.1(0.6)^{* *}$ & $36.9(0.4)$ & $36.9(0.4)$ & 0.29 \\
\hline \multicolumn{5}{|l|}{ Capillary Perfusion (seconds) } \\
\hline Baseline & $1(0)$ & $1(0)$ & $1(0)$ & \\
\hline IVC clamp & & $2(1)$ & $2(0)$ & \\
\hline SCR & $1(0)^{* *}$ & $4(2)$ & $6(2)$ & $<0.05$ \\
\hline \multicolumn{5}{|l|}{ Bowel Color \# } \\
\hline Baseline & $1(0)$ & $1(0)$ & $1(0)$ & \\
\hline IVC clamp & & $2(0)$ & $2(0)$ & \\
\hline SCR & $1(0)^{* *}$ & $2(1)$ & $3(1)$ & 0.05 \\
\hline Urine Output (mL) & $0.20(0.02)$ & $0.18(0.02)$ & $0.14(0.02)$ & $<0.05$ \\
\hline Intestinal W/D Ratio & $3.820(0.115)$ & $4.168(0.258)$ & $4.731(0.271)$ & $<0.05$ \\
\hline
\end{tabular}

*SCR denotes shunt clamp release: all clamps from portal vein and IVC are released at completion of shunt; **Sham rat values at completion of procedure; \# Bowel Color: 1-pink, 2-pink/purple, 3-purple; § Denotes comparison between c-clamp and cross clamp groups.

tract and isolated to about $1.5 \mathrm{~cm}$ in length, with gastroduodenal vein sectioned between ligatures (6:0's). Further isolation of the hepatic artery was completed by dissecting the fibrous tract along the hilar end of the portal vein (2-4). Subsequently, the inferior vena cava was dissected from the hepatic parenchyma to the right renal vein to an approximate length of $1.5 \mathrm{~cm}$.

\subsection{Shunt Creation}

The type of procedure was randomly identified by an assistant prior to time of clamp placement. A micro-serrifine vascular clamp (Fine Science Tools, jaw width 1 $\mathrm{mm}$ ) was modified to create a clamp that would only partially occlude the IVC. A c-clamp or regular clamp 
was brought to the field. The IVC was cross clamped above and below the venotomy site or partially clamped using a c-clamp, above the renal veins. Partial clamping was verified by direct intraoperative examination of the IVC. A $4 \mathrm{~mm}$ incision was made along the medial aspect of the occluded wall of the IVC using a Phaco blade. The portal vein was subsequently ligated at the bifurcation and a clamp was placed on the distal end of the isolated portal vein. A partial venotomy was performed on the lateral aspect of the hepatic end of the portal vein. This approach increased the size of the portal vein aperture so as to match the corresponding IVC opening (12). A portal vein clamp was used to approximate the apertures of the IVC and portal vein to facilitate the anastomosis. The upper pole of the portal vein was stitched to the corresponding upper pole of the IVC with 9:0 Prolene (Ethicon, NJ). The posterior walls of the veins were secured in continuous running suture to the inferior pole at which point the needle was exteriorized from the inferior pole of the IVC. The anterior walls were secured in a continuous running suture up to the superior pole. The portal vein clamp was temporarily released to remove air from the anastomosis line. The upper pole was secured completing the anastomosis.

\section{Statistical Analysis}

Results are expressed as median and ranges. The data was analyzed by parametric (two sided ttest) and nonparametric tests (Wilcoxon Rank Sum Test) where appropriate. Associations between variables were determined by linear regression analysis and Pearson's correlation coefficient using SPSS17 (Chicago, IL, licensed to CWRU). Statistical significance was considered to be achieved at a $p<0.05$.

\section{Results}

Animal weights, procedure OR time and anesthesia time as well as baseline hemodynamic parameters were comparable among groups (Table 1). In contrast, there were significant differences in the hemodynamic parameters after IVC clamp placement and shunt clamp release when groups were compared. The c-clamp technique had statistically significant greater mean arterial pressures after IVC clamp placement and shunt clamp release (Figure 1), higher urine output (Figure 2) and faster capillary refill at the completion of the shunt procedure. The median MAP after IVC clamping was 63 (range, 8) $\mathrm{mmHg}$ in the c-clamp group and 47 (range, 10) $\mathrm{mmHg}$ in the cross clamp group ( $\mathrm{p}<0.05$, Wilcoxon rank sum test).

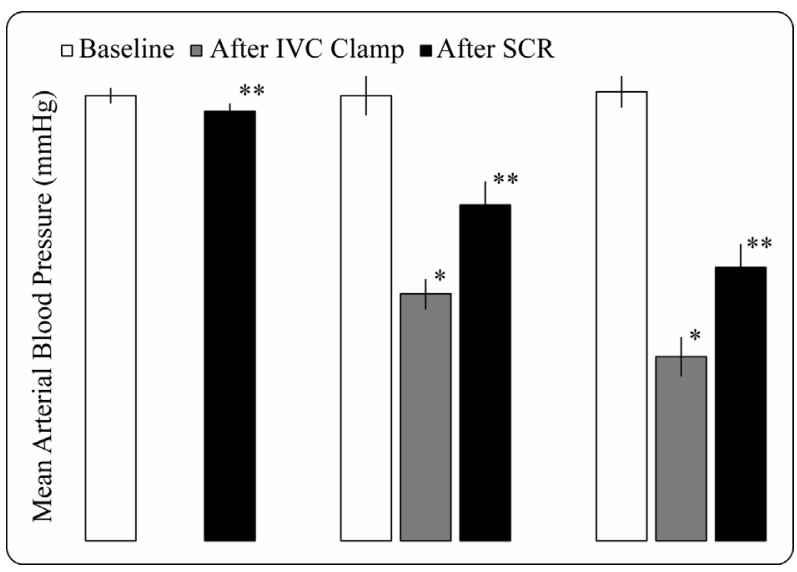

Figure 1. Mean arterial pressure at baseline, Two minutes after IVC clamp placement and Two minutes after shunt clamp release. $(*, * * p<0.05-$ Denotes statistical significance between groups).

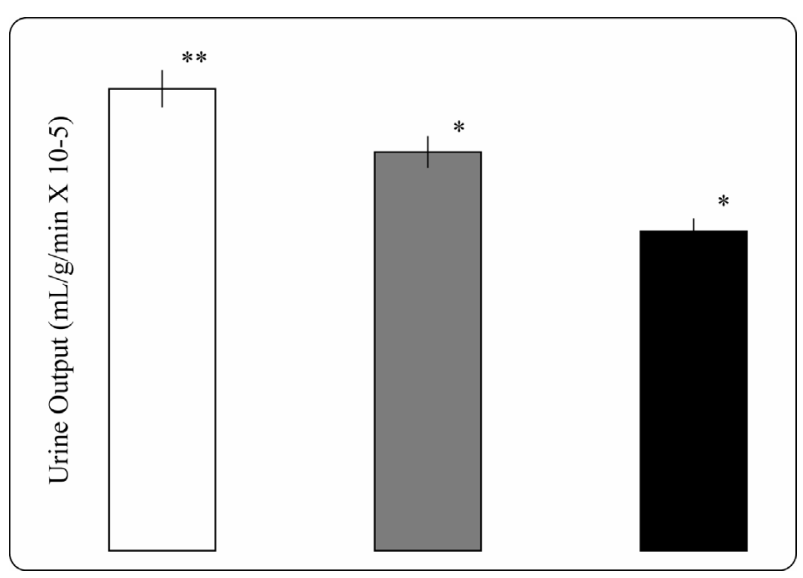

Figure 2. Urinary output at completion of portacaval shunt. $\left({ }^{*}, * p<0.05\right.$ - Denotes statistical significance between groups).

After shunt clamp release, MAP demonstrated a similar pattern (c-clamp group 86 (range, 12) mmHg vs cross clamp group 71 (range, 9) mmHg, p < 0.05, Wilcoxon rank sum test). Urine production was significantly greater in the sham group [0.20 (range, 0.02) $\mathrm{mL}, \mathrm{p}<0.05$ ] when compared to the c-clamp group [0.18 (range, 0.02) $\mathrm{mL}, \mathrm{p}<0.05$ ] and the cross-clamp group [0.14 (range, 0.02) $\mathrm{mL}, \mathrm{p}<0.05$, Wilcoxon rank sum test]. Further analysis was performed to evaluate for correlation between the mean arterial pressure and the rate of urine output. The results demonstrated a significant positive linear relationship between mean arterial pressure after IVC clamp placement for both c-clamp and cross clamp groups (Pearson's correlation coefficient, cclamp: $\mathrm{r}=$ 0.95, cross clamp: $r=0.96)$. Sustained mean arterial pressure after IVC clamp placement correlates with increased urine output, suggesting improved renal perfusion and GFR. In addition, the evaluation of capillary 


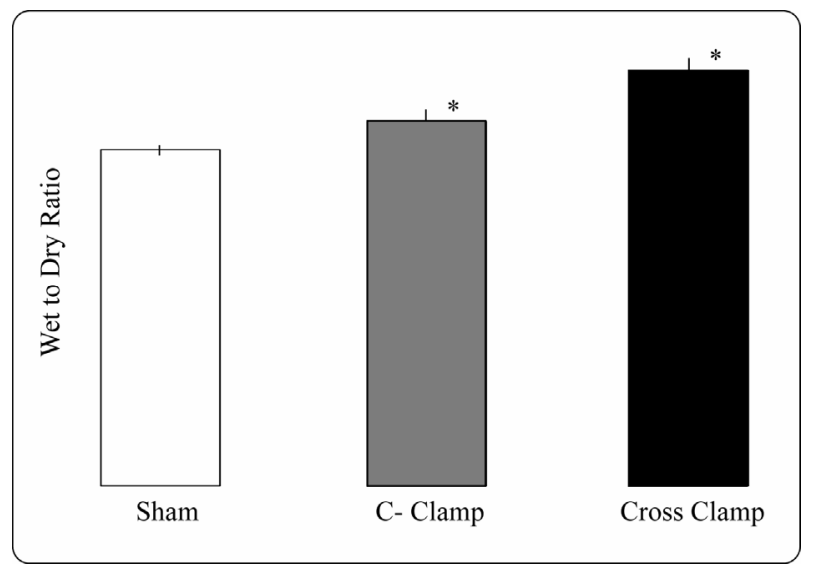

Figure 3. Small bowel wet-to-dry ratio, a surrogate for intestinal edema. $\left({ }^{*} p<0.05\right)$.

perfusion was used as a surrogate of not only intestinal perfusion but of peripheral perfusion. After shunt clamp release, there was a statistically significant difference in capillary refill time between the c-clamp group and the cross clamp group [4 (range, 2) vs 6 (range, 2) seconds, $\mathrm{p}<0.05$, Wilcoxon rank sum test].

To examine bowel edema, intestinal wet-to-dry ratios were measured at the proximal small intestine in each animal. The data reveals a statistically significant higher ratio of tissue water content in the cross clamp group [4.731 (range, 0.271)] when compared to the c-clamp group [4.168 (range, 0.258)] and sham group [3.820 (range, 0.115), $\mathrm{p}<0.05$, Wilcoxon rank sum test] (Figure 3). A significant difference was also noted in the tissue water content between the cclamp and sham rat groups. Further analysis demonstrated a significant negative linear relationship between mean arterial pressure (MAP) after IVC clamp placement and intestinal wet-todry ratio (Pearson's correlation coefficient, c-clamp: $r=$ -0.95 , cross clamp: $r=-0.95$ ). The degree of reduction in mean arterial pressure is associated with increased intestinal wet-todry ratio, thus, greater intestinal edema.

\section{Discussion}

The rat portacaval shunt is a reliable model of portosystemic hepatic encephalopathy (1-4), but remains a technically demanding exercise. To the best of our knowledge, the present study is the first one to use objective intraoperative hemodynamic parameters to evaluate a modified portacaval shunt procedure. Our results showed significantly greater hemodynamic stability in the animals that underwent the portacaval shunt using the c-clamp compared to the cross clamp technique. While surgical and anesthesia time can impact hemodynamic stability, their effects were comparable among the groups. The use of this technique may enhance the interpretation of future research in encephalopathy by decreasing surgical bays.

Consistent with previous animal studies [17, 18], we demonstrated a significant linear correlation between MAP and tissue perfusion. The severity of hypotension after IVC clamp placement predicts the degree of intestinal edema and the reduction in renal perfusion resulting in decreased urine output. Studies in dogs and rodents have demonstrated that rapid changes in arterial pressure result in changes in urine production $[17,18]$. Steele and colleagues demonstrated significant changes in urine flow in an average of 6 seconds following changes in arterial pressure [18]. Consistent with these findings, the transient reduction in mean arterial pressure after IVC clamp placement resulted in significantly diminished urine production in both groups (c-clamp and cross clamp) versus sham operated controls. Human studies further corroborate this finding, demonstrating that renal perfusion is significantly reduced in shock and the reduction of urine production is proportional to the severity of hypotension $[19,20]$.

By sustaining venous return, the specially designed c-clamp maintains greater hemodynamic support. Analogous to rat shock models, the intraoperative parameters in the cross clamp group revealed significant hypotension resulting in greater intestinal ischemia and edema [21-23]. Intestinal hypoxia and ischemia result in bowel edema and increased microvascular permeability [21-24]. This leads to increases in gut derived LPS in the circulation resulting in the release of oxygen free radicals and TNF [21,22]. In animal models, LPS concentrations are significantly elevated as early as 25 minutes after induction of shock [24]. Therefore, greater hemodynamic stability seen in the c-clamp group places the animals under less stress and reduces the likelihood of ischemic damage to the bowel.

The reduction in cardiac output associated with the cross clamp technique establishes factors that may complicate the study of hepatic encephalopathy in this animal model. Tissue hypoperfusion secondary to portal vein and IVC occlusion in humans results in multiple metabolic abnormalities including hypocalcemia, hyperkalemia, hypoxia, and subsequent metabolic acidosis [21-26]. In rodent studies, electrolyte abnormalities such as hypocalcemia can lead to activation of specific calcium channels (csNSC) resulting in altered neuronal inhibition [27]. Furthermore, transient periods of cerebral ischemia have been implicated in the elevation of peripheral type benzodiazepine receptor (PTBR) densities [28-31]. Expressed on normal astrocytes, the upregulation of PTBR's leads to the production of specific neurosteroids that activate the GABA receptor enhancing further neural inhibition. In addition, the systemic in- 
flammatory response observed with hypotension, i.e. TNF and IL-1 production, also upregulates PTBR expression [28,29,32]. These mechanisms of neurological dysfunction have been implicated in traumatic brain injury, focal cerebral ischemia, global cerebral ischemia and hepatic encephalopathy [31,33,34]. Thus, the severity of hypotension associated with the cross clamp technique may result in the upregulation of PTBR densities thereby potentiating any neural inhibition and confounding investigations in the rat model of hepatic encephalopathy.

Limitations of the study include the subjective nature of accounting for respiratory rate and assessment of bowel capillary perfusion. Data for heart rate was limited to the baseline line measurement as the Digimed BP analyzer machine could not accurately assess heart rates below a blood pressure of $90 \mathrm{mmHg}$. Further, the relatively small sample size in each group is a limitation in defining the statistical power of the results and a larger scale study is needed to confirm these findings.

Based on the results of the present study, we conclude that partial clamping of the IVC results in greater hemodynamic stability compared to the traditional cross clamp technique in the construction of the portacaval shunt. Therefore, the technique offers the potential for increased animal survival and a model with fewer confounding factors affecting the study of portosystemic hepatic encephalopathy.

\section{References}

[1] E. J. Smanik, K. D. Mullen, W. G. Giroski and A. J. McCullough, "The Influence of Protacaval Anastomosis on Gonadal and Anterior Pirtuitary Hormones in a Rat Model Standardized for Gender, Food Intake, and Time after Surgery,” Steroids, Vol. 56, 1991, pp. 237-247. doi:10.1016/0039-128X(91)90040-3

[2] S. H. Lee and B. Fisher, "Portacaval Shunt in the Rat," Surgery, Vol. 50, No. 4, 1961, pp. 668-672.

[3] R. Herz, V. Savtter, F. Robert and Bircher J, "The Eck fistula Rat: Definition of an Experimental Model,” European Journal of Clinical Investigation, Vol. 2, No. 6, 1972, pp. 390-397. doi:10.1111/j.1365-2362.1972.tb00667.x

[4] S. Lee, J. G. Chandler, C. E. Broelsch, Y. M. Flamant and M. J. Orloff, "Portal-Systemic Ansastomosis in Rat," Journal of Surgical Research, Vol. 17, No. 1, 1974, pp. 53-73. doi:10.1016/0022-4804(74)90168-1

[5] R. B. Rutherford, "Basic Vascular Surgical Techniques," WB Saunders, Vol. 1, No. 5, 2000, pp. 484-486.

[6] E. M. Brznock, "Surgical Manipulations of Potosystemic Shunts in Dogs," Journal of the American Veterinary Medical Association, Vol. 174, No. 8, 1979, pp.819-826.

[7] K. Weinbren, S. L. Washington and C. Y. Smith, "The
Response of the Rat Liver to Alterations in Total Portal Blood Flow," British Journal of Experimental Pathology, Vol. 56, No. 2, 1975, pp. 148-156.

[8] P. Sharma, "Improved Survival Rate after Portacaval Shunt in the Rat Using a Modified Microsurgial Technique," European Surgical Research, Vol. 27, No. 2, 1995, pp. 134-136. doi:10.1159/000129384

[9] M. B. Khosravi, H. Jalaeian, M. Lahsaee, S. Ghaffaripour, H. Salahi and A. Bahador, "The Effect of Clamping of Inferior Vena Cava and Portal Vein on Urine Output during Liver Transplantation," Transplantation Proceedings, Vol. 39, No. 4, 2007, pp. 1197- 8. doi:10.1016/j.transproceed.2007.02.057

[10] W. Zhou, A. Li, Z. Pan, S. Fu, Y. Yang, L. Tang, Z. Hou and M. Wu, "Selectiv E Hepatic Vascular Exclusion and Pringle Maneuver: A Comparative Study in Liver Resection,” European Journal of Surgical Oncology, Vol. 34, No. 1, 2008, pp. 49-54. doi:10.1016/j.ejso.2007.07.001

[11] J. M. Funovics, M. G. Cummings, L. Shuman, J. H. James and J. E. Fischer, "An Improved Nonsuture Method for Portacaval Anastomosis in the Rat," Surgery, Vol. 77, No. 5, 1975, pp. 661- 664.

[12] F. Sánchez-Patán, R. Blanco, M. A. Aller, R. Anchuelo, F. S. Román and J. Arias, "End-To-Side Portacaval Shunt: a Simplified Technique,” Journal Of Investigative Surgery, Vol. 20, No. 2, 2007, pp. 135-138.

[13] S. Welch, "A Technique for Portacaval Anastomosis (Eck Fistula),” Surgical Gynecology and Obstetrics, Vol. 85, 1947, p. 492.

[14] G. Jacob, S. Howe, Hobbs and K. A. Caval, "Clamp for Portacaval Shunt in the Rat,” Laboratory Animals, Vol. 18, No. 1, 1984, pp. 20-21. doi:10.1258/002367784780865009

[15] D. L. Coy, A. Srivastava, J. Gottstein, R. F. Butterworth and A. T. Blei, "Postoperative Course after Portacaval Anastomosis in Rats is Determined by Protacaval Pressure Gradient," American Journal of Physiology, Vol. 261, No. 6, 1991, pp. 1072-1078.

[16] R. Radakrishnan, K. Shah, H. Xue, S. Moore-Olufemi and F. Moore, "Measurement of Intestinal Edema Using an Impedance Analyzer Circuit," Journal of Surgical Research, Vol. 138, No. 1, 2007, pp. 106-110. doi:10.1016/j.jss.2006.06.009

[17] P. H. Brand, K. B. Coyne, K. A. Kostrzewski, P. Shier and P. J. Metting, "Pressure Dieresis and Autonomic Function in Conscious Dogs," American Journal of Physiology, Vol. 261, No. 4, 1991, pp. 802-810.

[18] J. E. Steele, P. H. Brand, P. J. Metting and S. L. Britton, "Dynamic, Short-Term Coupling between Changes in Arterial Pressure and Urine Flow," American Journal of Physiology, Vol. 265, No. 5, 1993, pp. 717-722.

[19] H. D. Lauson, S. E. Bradley, A. Cournand and V. V. Andrews, "The Renal Circulation In Shock," Journal of Clinical Investigation, Vol. 23, No. 3, 1944, pp. 381-402. doi:10.1172/JCI101506

[20] M. A. Hayes, "The Influence of Shock without Clinical Renal Failure on Renal Function,” Annals of Surgery, Vol. 
146, No. 4, 1957, pp. 523-7. doi:10.1097/00000658-195710000-00001

[21] E. Eleftheriadis, K. Kotzampassi, K. Papanotas, N. Heliadis and K. Sarris, Gut Ischemia, "Oxidative Stress, and Bacterial Translocation in Elevated Abdominal Pressure in Rats,” Vol. 20, No. 1, 1996, pp. 11-6.

[22] J. Jiang, S. Bahrami, G, Leichtfried, H. Redl, W. Ohlinger and G. Schlag, "Kinetics of Endotoxin and Tumor Necrosis Factor Appearance in Portal and Systemic Circulation after Hemorrhagic Shock in Rats," Annals of Surgery, Vol. 221, No. 1, 1995, pp. 100-106. doi:10.1097/00000658-199501000-00012

[23] J. R. Braz, P. Nascimento, O. Paiva Filho, L. G. Braz, L. A. Vane, P. T. Vianna, G. R. Rodrigues, "The Early Systemic and Gastrointestinal Oxygenation Effects of Hemorrhagic Shock Resuscitation with Hypertonic Saline and Hypertonic Saline 6\% Dextran-70: a Comparative Study in Dogs,” Anesthesia \& Analgesia, Vol. 99, No. 2, 2004, pp. 536-546. doi:10.1213/01.ANE.0000122639.55433.06

[24] G. D. Bottoms, "Plasma concentrations of Endotoxin Following Jugular or Portal Vein Ligation,” Circulation Shock, Vol. 33, 1991, pp. 1-6.

[25] M. Nakasuji and M. Bookallil, "Pathophysiological Mechanisms of Postrevascularization Hyperkalemia in Orthotopic Liver Transplantation,” Anesthesia \& Analgesia, Vol. 91, No. 6, 2000, pp. 1351-1355. doi:10.1097/00000539-200012000-00008

[26] I. Hilmi and R. Planinsic, "Con: Venovenous Bypass Should Not Be Used In Orthotopic Liver Transplantation," Journal Of Cardiothoracic And Vascular Anesthesia, Vol. 20, No. 5, 2006, pp. 744-747. doi:10.1053/j.jvca.2006.06.004

[27] X. P. Chu, X. M. Zhu, W. L. Wei, G. H. Li, R. P. Simon, J. F. MacDonald and Z. G. Xiong, "Acidosis Decreases Low $\mathrm{Ca}(2+)$-Induced Neuronal Excitation by Inhibiting the Activity of Calciumsensing Cation Channels in Cultured Mouse Hippocampal Neurons,” Journal of Physiology, Vol. 550 , No. 2, 2003, pp. 385-399. doi:10.1113/jphysiol.2003.043091

[28] T. R. Sairanen, P. J. Lindsberg, M. Brenner and A. L. Sirén, "Global Forebrain Ischemia Results in Differential Cellular Expression of Interleukin-1beta (IL-1beta) and Its Receptor at Mrna and Protein Level," Journal of Cerebral Blood Flow \& Metabolism, Vol. 17, No. 10, 1997, pp.1107-1120. doi:10.1097/00004647-199710000-00013
[29] H. Uno, T. Matsuyama, H. Akita, H. Nishimura and M. Sugita, "Induction of Tumor Necrosis Factor-Alpha in the Mouse Hippocampus Following Transient Forebrain Ischemia,” Journal of Cerebral Blood Flow \& Metabolism, Vol. 17, No. 5, 1997, pp. 491-9. doi:10.1097/00004647-199705000-00002

[30] V. L. Rao, K. K. Bowen, A. M. Rao and R. J. Dempsey, "Up-Regulation of the Peripheral-Type Benzodiazepine Receptor Expression and [(3)H] PK11195 Binding in Gerbil Hippocampus after Transient Forebrain Ischemia," Journal of Neuroscience Research, Vol. 64, No. 5, 2001, pp. 493-500.doi:10.1002/jnr.1101

[31] J. Benavides, A. Dubois, B. Gotti, F. Bourdiol and B. Scatton, "Cellular Distribution of Omega 3 (Peripheral Type Benzodiazepine) Binding Sites in the Normal and Ischaemic Rat Brain: an Autoradiographic Study with the Photoaffinity Ligand [3H] PK 14105," Neuroscience Letters, Vol. 114, No. 1, 1990, pp. 32-38. doi:10.1016/0304-3940(90)90424-8

[32] F. Bourdiol, S. Toulmond, A. Serrano, J. Benavides, B. Scatton, "Increase in Omega 3 (Peripheral Type Benzodiazepine) Binding Sites in the Rat Cortex and Striatum after Local Injection of Interleukin-1, Tumour Necrosis Factor-Alpha and Lipopolysaccharide,” Brain Research, Vol. 543, No. 2, 1991, pp. 194- 200. doi:10.1016/0006-8993(91)90028-T

[33] V. L. Raghavendra Rao, A. Dogan, K. K. Bowen and R. J. Dempsey, "Traumatic Brain Injury Leads to Increased Expression of Peripheral-Type Benzodiazepine Receptors, Neuronal Death, and Activation of Astrocytes and Microglia in Rat Thalamus,” Experimental Neurology, Vol. 161, No. 1, 2000, pp. 102-114. doi:10.1006/exnr.1999.7269

[34] V. L. Rao, R. Audet, G. Therrien and R. F. Butterworth, "Tissue-Specific Alterations of Binding Sites for Peripheral-Type Benzodiazepine Receptor Ligand [3H] PK11195 in Rats Following Portacaval Anastomosis,” Digestive Diseases and Sciences, Vol. 39, No. 5, 1994, pp. 1055-63. doi:10.1007/BF02087558

[35] F. Bourdiol, S. Toulmond, A. Serrano, J. Benavides and B. Scatton, "Increase in Omega 3(Peripheral Type Benzodiazepine) Binding Sites in the Rat Cortex and Striatum after Local Injection of Interleukin-1, Tumour Necrosis Factor-Alpha and Lipopolysaccharide,” Brain Research, Vol. 543, No. 2, 1991, pp. 194- 200. doi:10.1016/0006-8993(91)90028-T 